\title{
An assessment of the interplay between literacy and digital Technology in Higher Education
}

\author{
Shahrokh Nikou ${ }^{1,2}$ (D) Milla Aavakare ${ }^{1}$ \\ Received: 9 October 2020 / Accepted: 21 January 2021/ Published online: 6 February 2021 \\ (C) The Author(s) 2021
}

\begin{abstract}
Digital technologies fundamentally transform teaching and learning in higher education environments, with the pace of technological change exacerbating the challenge. Due to the current pandemic situation, higher education environments are all now forced to move away from traditional teaching and learning structures that are simply no longer adaptable to the challenges of rapidly changing educational environments. This research develops a conceptual model and employs Structural Equation Modelling (SEM) using Partial least Squares (PLS) to examine the impact of information and digital literacy on 249 Finnish university staff and students' intention to use digital technologies. The findings show the complex interrelationship between literacy skills and digital technologies among university staff and students. The results illustrate that information literacy has a direct and significant impact on intention to use; while, unlike our expectation, digital literacy does not have a direct impact on the intention to use. However, its effect is mediated through performance expectancy and effort expectancy. The authors suggest that to understand the changes that are taking place in higher education environment, more attention needs to be paid to redefining policies and strategies in order to enhance individuals' willingness to use digital technologies within higher education environments.
\end{abstract}

Keywords Digital literacy; higher education; information literacy · Digital technology · University staff and students · UTAUT

Shahrokh Nikou

shahrokh.nikou@abo.fi

Milla Aavakare

milla.aavakare@abo.fi

1 Information Studies, Åbo Akademi University, Fänriksgatan 3B, 20500 Turku, Finland

2 Department of Computer and Systems Sciences, Stockholm University, Stockholm, Sweden 


\section{Introduction}

Higher education environments, among others, are still struggling to come to terms with digitalisation and trying to find optimal ways to maximise the benefits such as higher student engagement levels, connecting traditional classroom to a virtual landscape and the enhancement of the student learning process (Gupta et al. 2020; Rabah 2015). The recent global crisis, and in particular the current pandemic situation, has required a major reform in higher education (Skulmowski and Rey 2020). As such, in response to these challenges, higher education institutions are now looking into accelerating the process of digitalisation and the transition from on-campus teaching to technology-enhanced learning - with an increasing focus on the move towards online and distance learning. To respond to this emerging issue, transition in many higher education institutions has already taken place although it was rushed and unplanned and are currently looking at fine-tuning processes, assessing and making improvements.

Digital technologies have become an integral part of daily activities in modern education, and the use of such technologies (e.g. computer-mediated communication (CMC) tools, subject-specific learning tools, interactive whiteboards, desktop or mobile videoconferencing, mobile applications/computer software, gaming consoles, tablets and smartphones (Desjardins and van Oostveen 2015; Major et al. 2018; van Oostveen and Desjardins 2013), is now even expected within formal learning environments (Lodge et al. 2019). Moreover, among other digital educational tools, learning management systems (LMSs) such as Moodle and Blackboard, while already in use (e.g. Carvalho et al. 2011) have recently gained popularity as essential tools within the field of education (Rachmadtullah et al. 2020). LMSs help to create, deploy, and maintain fully digital forms of education and provide a meaningful e-learning experience for users of such systems. Learning management systems (LMSs) provide many benefits and advantages to teachers (e.g. by facilitating the tracking of learner progress and performance) and to students (e.g. by integrating social learning experiences into learning strategy) (Sarrab et al. 2013; Zheng et al. 2018) the effective and efficient use of such technologies depends on prerequisite skills such as digital literacy and information literacy (Avc1 and Ergün 2019; Tang and Chaw 2016).

Moreover, other authors such as (Turnbull et al. 2019) stated that learning management systems (LMSs) not only provide content to learners and enable to (i) disseminate knowledge, (ii) assess the learner competency, (iii) record the learner attainment, but also facilitate timely and accurate communication between learners and teachers and provide support for online social communities. All in all, we argue that in the higher education context, the development of a set of competencies that enables efficient and effective use of digital technologies is critical requisite for students' success and lifelong learning.

While, in our information-based society, literacy skills have become survival skills for economic development and community well-being (Desjardins 2001). Within higher education literacy is considered an essential enabler for problem solving, critical thinking, lifelong learning, and to function adequately for both veteran educators (Pastore and Andrade 2019; Záhorec et al. 2019), and new generations of students (Gullikson 2006; Leahy and Dolan 2010). Blau and Shamir-Inbal (2017, p. 781) found that the use of ICT in their lessons and enhancing their pedagogical skills, their digital 
competence all impacts the general ICT integration into education. Furthermore, as distance education has become a trend in modern teaching and learning, research on intention to use digital technology once again has attracted the attention of several scholars from different disciplines (e.g. Lazar et al. 2020; Liu et al. 2020). As such, not only is it important to investigate the impact of digital and information literacy skills on education but concurrently to pay equal attention to individuals' intention to use digital technology. In this paper, digital literacy refers to "the awareness, attitude and ability of individuals to appropriately use digital tools and facilities to identify, access, manage, integrate, evaluate, analyse and synthesise digital resources" (Martin 2006, p. 155). Information literacy refers to "the understanding and set of abilities enabling individuals to recognise when information is needed and have the capacity to locate, evaluate and use effectively the needed information" (American Library Association (ALA) 2000). However, few studies have been conducted on these aspects. Within higher education, these two aspects - (i) literacy skills and (ii) intention to use digital technologies for teaching and learning purposes (e.g. Anthonysamy et al. 2020; Jeffrey et al. 2011; Nikou et al. 2018) — have been extensively investigated, but seldom together.

In addition, from a theoretical standpoint, different models have been used to assess intention to use digital technology within higher education. For instance, Almaiah et al. (2019), employed an integrated model of the unified theory of acceptance and use of technology (UTAUT), to assess university students' intention to use handheld devices for learning (i.e. mobile learning or "m-learning"). To investigate literacy skills among teachers, Georgina and Hosford (2009, p. 695), examined university staff's perception towards digital skills and found that empowering a university-wide professoriate to enhance both their information literacy and technology literacy skills is the new goal in higher education. Regarding students' literacy skills, recent studies have indicated that literacy skills play a vital role in students' education and performance (e.g. Foo et al. 2014; Kanniainen et al. 2019). For example, Kanniainen et al. (2019), found that literacy skills impact students' online research and comprehension (ORC) performance.

To this end, the main objectives of this research were twofold: (1) based on the existing theoretical models (e.g. $\mathrm{Ng} 2012$; Venkatesh et al. 2003), it aimed to develop an integrated conceptual model to assess the factors that influence Finnish university staff and students' intention to use digital technologies, and (2) through an empirical research, it aimed to create new information and knowledge concerning the interplay between literacy skills and intention to use digital technology. Primarily, this research was conducted to answer the following question: "To what extent do the literacy skills of university staff and students influence their intentions to use technology, and how does effort expectancy and performance expectancy mediate these relationships"?

To assess the above-mentioned question, a series of hypotheses were proposed, and data was collected via an online questionnaire completed by university staff (e.g. professors and researchers) and students. The data was analysed through structural equation modelling (SEM) using SmartPLS v.3.

The remainder of this paper is structured as follows: section two provides a literature review; section three, based on the review results, describes a theory-based conceptual model and puts forward several hypotheses. Section four describes the research methodology followed by research results. Section six provides the discussion and section seven offers a final conclusion. 


\section{Literacy competences}

While there is no commonly accepted definition of literacy or what it means to be literate (Keefe and Copeland 2011), the concept of literacy is traditionally thought of as the ability to read and write. Literacy skills are fostered in the educational system; they are intertwined with our everyday activities and can be utilised in measuring a population's level of education. However, alongside the development of our contemporary society, often referred to a knowledge-based economy, the concept of literacy has evolved and gone past its traditional definition. For example, the concept of twentyfirst century digital skills, which includes abilities such as collaboration, communication, digital literacy, citizenship, problem solving, critical thinking, interpersonal capabilities, creativity and productivity has extensively been discussed in the literature (Dede 2010; Van Laar et al. 2017). Lewin and McNicol (2015) argued that twentyfirst century skills are essential individual competencies in our contemporary digital workplace. Moreover, Shields and Chugh (2018) critically reviewed the concept of twenty-first century skills and argued that there is a strong rationale for the teaching of twenty-first century skills to students. The authors claimed that it cannot be assumed that because learners in the twenty-first century use Information and Communications Technology (ICT) in their education, they know how to use the technology effectively and efficiently for performing different activities (p. 1105).

In the context of twenty-first century skills, forms of literacy such as information literacy (e.g. Eisenberg 2008; Lloyd 2006), and digital literacy (e.g. Eshet-Alkalai 2004; Ng 2012), are now regarded as highly important in terms of achieving success in higher education. In this paper, while we acknowledge the importance of twenty-first century skills in the higher education context, we specifically focus on information and digital literacy as the development of such abilities not only is critical requisite for students' success in online learning environments, but also the acquisition of these skills is one of the necessary tools for facilitating lifelong learning (Ala-Mutka 2011). Information and digital literacy skills provide an array of abilities - for example, to (i) access and search for information efficiently and effectively using a variety of digital tools, (ii) critically evaluate the reliability of sources for an academic context, (iii) filter, manage, and organise information from a wide variety of sources, and (iv) understand how to use digital tools for referencing to avoid plagiarism. Abilities in relation to evaluation and effective use of information have always been a central component of learning but recently have reached a new level of significance in the modern era as they have morphed into a "survival skill" (Eshet-Alkalai 2004).

As defined by Eshet-Alkalai (2004), information literacy encompasses "the cognitive skills that consumers use to evaluate information in an educated and effective manner" (p. 101). An alternative definition by the American Library Association (American Library Association (ALA) 2000), on the other hand, states that information literacy encompasses abilities related to recognising when information is needed and then being able to locate, evaluate, and use information effectively. Information literacy has received scholarly attention regarding all levels of formal education, as studies have been conducted on topics ranging from early childhood education to tertiary education (e.g. Dunn 2002; Gross and Latham 2012; Heider 2009; von Loh and Henkel 2014). Digital literacy, on the other hand, encompasses "the multiplicity of skills associated with the use of digital technologies" (Ng 2012, p. 1066). The utilisation of digital 
technologies may involve the employment of hardware and software for varying tasks within a multitude of activities, an evident example being for teaching and learning purposes. Colwell et al. (2013), stated that digital literacy skills are increasingly important in developing informed citizens who can critically evaluate information and ideas. Other authors such as Jacobs (2006), argued that digital literacy skills could have implications for how younger generations are being prepared for participation in today's society. The concept of digital literacy has; however, caused ambiguity owing to the wide usage within differing contexts (Eshet-Alkalai 2004). To combat this notion, scholars have proposed frameworks aimed at clarifying the process. For example, $\mathrm{Ng}$ (2012), considers the concept of digital literacy as the intersection of a technical dimension, a cognitive dimension, and a socio-emotional dimension. In addition to information literacy, digital literacy has also gained its share of scholarly attention in relation to the educational setting (e.g. Lea and Jones 2011; Meyers et al. 2013).

To date, the concept of literacy has been explored as an area of research within the context of a technology acceptance and in association with UTAUT model. Mohammadyari and Singh (2015), have looked at digital literacy and the impact of UTAUT constructs on intention to continue using IT as the proximal predictor of performance. The authors hypothesised that digital literacy impacts performance through performance expectancy and effort expectancy. The constructs of performance expectancy and effort expectancy originate from the unified theory of acceptance and use of technology (UTAUT) model developed by Venkatesh et al. (2003). The UTAUT model was originally developed within an organisational context and a consumer context in order to investigate use behaviour. Mohammadyari and Singh (2015), altered some of the UTAUT constructs, resulting in a model that consisted of performance expectancy, effort expectancy, social influence, continuance intention to use IT, and performance, in addition to digital literacy. The findings indicated that digital literacy has a positive effect on performance expectancy and effort expectancy, whereas performance expectancy affects continuance intention to use IT, which in turn affects overall performance (Mohammadyari and Singh 2015). However, further research and development on the topic are needed and that digital literacy requires an expanded research focus from the perspective of information technology usage as an evolving skill (Mohammadyari and Singh 2015).

\section{Theoretical background}

The present research extends UTAUT by including digital literacy and information literacy as key predictors of the intention to use digital technologies for teaching and learning purposes. Digital literacy and information literacy are particularly relevant in the context of higher education because they allow us to conceptualise the use of the educational digital technologies as an evolving skill. Despite the accolades given to UTAUT and UTAUT2 constructs for their predictive ability, and based on the context of the study, constructs such as hedonic motivation, habit, and social influence have been deliberately excluded from the model. For instance, use behaviour, which is the outcome variable in the UTAUT models (Venkatesh et al. 2003; Venkatesh et al. 2012), was not selected for the present study because we did not investigate the actual 
usage, but rather the intention to use. Hedonic motivation was excluded owing to the fact that university staff and students are required to utilise digital technologies in their work tasks; thus, assessing the pleasure derived from the use of technology was less relevant in the context of the research at hand. The same reasoning was applied to habit, as the usage of certain digital technologies is dictated by circumstances. The constructs of social influence and facilitating conditions were excluded, as they are external variables and thus not considered to occur within the realms of information literacy and digital literacy. Finally, the construct of price value was excluded owing to this research being carried out at some Finnish universities, meaning that staff and students had free access to technologies on campus.

Figure 1 shows our research model. We adapted UTAUT by including digital literacy (DL) and information literacy (IL) as additional predictors of university staff and students' intention to use digital technologies (INT) in addition to the two core constructs of UTAUT, performance expectancy (PE) and effort expectancy (EE). The following sections detail our reasons for these alterations in the model and explicate the hypotheses in the model.

\subsection{Information literacy}

According to the American Library Association (ALA) (2000), information literacy is defined as abilities related to recognising when information is needed and then being able to locate, evaluate, and use information effectively. As noted by Johnston and Webber (2003), IL emphasis on recognising an information need, evaluating what is found, and using the information effectively. The relationship between IL and intention to use digital technology has been investigated by, for example, Alateyah et al. (2013) and Kong et al. (2019). Furthermore, previous studies by Nikou et al. (2018, 2019), have indicated a significant relationship between IL and attitude towards the use of digital technologies, and attitude in turn was found to have a significant effect on intention to use. Within the context of the UTAUT framework, the influence of its constructs on IL has received some scholarly attention (e.G. Ali and Gupta 2019).

In the present paper, we propose that a higher level of IL has a direct effect on intention to use digital technology, but also positively affects the productivity of university students and staff. In other words, a higher level of IL will influence staff

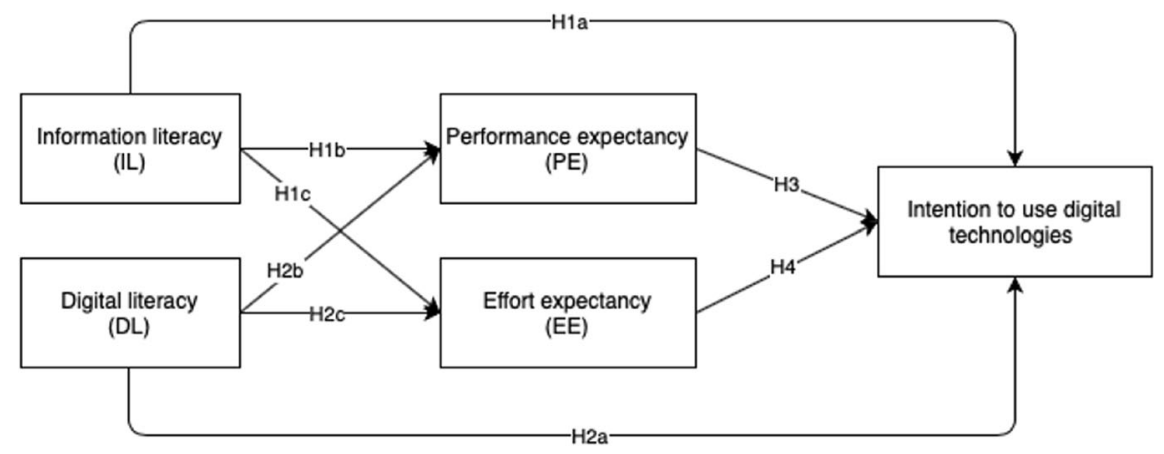

Fig. 1 Conceptual model 
and students' performance and effort expectations in relation to using digital technology for teaching and learning purposes. Thus, these relationships may be represented by the following hypotheses:

H1a: Information literacy has a positive effect on intention to use digital technology

H1b: Information literacy has a positive effect on performance expectancy

H1c: Information literacy has a positive effect on effort expectancy

\subsection{Digital literacy}

In this paper, digital literacy (DL) is characterised as a mixture of technical, cognitive, and socio-emotional factors associated with the utilisation of digital technologies $(\mathrm{Ng}$ 2012). A relationship between DL and intention to use has been investigated in the research of, for example, Bayrakdaroğlu and Bayrakdaroğlu (2017). Moreover, previous research by Nikou et al. (2018) has indicated that a significant relationship exists between certain components of DL (i.e. technical and social-emotional factors) and attitude towards the use of digital technologies, and in turn towards intention to use digital technologies. In the context of the UTAUT2 model, prior research by Mohammadyari and Singh (2015), has indicated that DL is positively related to performance expectancy and effort expectancy. Therefore, we propose that a higher level of DL not only has a direct effect on intention to use digital technology but also positively influences the productivity of university staff and students. In other words, DL has a direct positive impact on staff and students' performance and effort expectations in relation to using digital technology for teaching and learning purposes. Thus, these relationships may be represented by the following hypotheses:

H2a: Digital literacy has a positive effect on intention to use digital technologies $H 2 b$ : Digital literacy has a positive effect on performance expectancy

H3c: Digital literacy has a positive effect on effort expectancy

\subsection{Performance expectancy}

Performance expectancy (PE) refers to the extent to which using digital technologies benefits university staff and students in performing their teaching and learning activities. The definition used in this research is an adaption of the PE construct used in the UTAUT model (Venkatesh et al. 2003), whereby the construct has been used within an organisational context and a consumer context. PE has received a varied level of scholarly attention within the educational context (e.g. Abu-Al-Aish and Love 2013; Chen 2011; Diep et al. 2016; Nassuora 2012). In terms of the effect of PE on intention, previous research has indicated that $\mathrm{PE}$ can indeed be a significant predictor of intention (e.g. Ghalandari 2012).

We propose that an individual with high levels of IL and DL skills may expect to put in less effort while using digital technology for teaching and learning activities, and simultaneously expect to exhibit a better performance. The hypothesis concerning this construct 
would indicate the existence of performance benefits achieved by its use (Chávez Herting et al. 2020). Consequently, this relationship may be represented by the following hypothesis:

H3: Performance expectancy has a positive effect on intention to use digital technology

\subsection{Effort expectancy}

Effort expectancy (EE) refers to the extent of ease associated with university staff and students' use of digital technology. The definition is likewise modified from its original context in the UTAUT model (Venkatesh et al. 2003). The EE has also received its share of scholarly attention within the educational context (e.g. Abu-Al-Aish and Love 2013; Chen 2011; Nassuora 2012). In terms of the effect of EE on intention to use technology, prior research (Ghalandari 2012; Lowenthal 2010), suggests that EE is a significant predictor of intention. In university contexts, the adoption of digital technologies may involve less time directed towards academic responsibilities such as teaching (research) and learning (Liu et al. 2020). In other words, if the use of technology requires a greater effort than non-use, one can speculate that use decreases accordingly. We theorise that an individual with high levels of IL and DL skills may expect to put in less effort while using digital technology for teaching and learning activities, and simultaneously expect to have a higher degree of ease associated with their use of technology. Therefore, this relationship may be represented by the following hypothesis:

\section{H4: Effort expectancy has a positive effect on intention to use digital technology}

\subsection{Intention to use digital technology}

Intention to use as an outcome variable has been used in seminal studies on technology use (Ajzen 1985; Davis 1989; Fishbein and Ajzen 1975; Venkatesh et al. 2012). In the research at hand, intention to use technology (INT) refers to university staff and students' intention to use digital technologies for teaching and learning purposes. In this research, we aimed to investigate how intention to use digital technology can be affected by information literacy and digital literacy while concurrently accounting for performance expectancy and effort expectancy. Moreover, we also assessed whether $\mathrm{PE}$ and EE mediate the relationships between DL and IL and intention to use.

\section{Research methodology}

The proposed conceptual model is assessed through partial least squares structural equation modelling (PLS-SEM). This approach is appropriate for exploratory research when seeking to develop theories (Hair et al. 2017). According to Hair et al. (2019) PLS-SEM facilitates the opportunity to "estimate complex models with many constructs, indicator variables and structural paths without imposing distributional assumptions on the data" (p. 2). 


\subsection{Measures}

To examine the path relationships among five constructs in the model, an online survey was designed. Items for measuring performance expectancy, effort expectancy and intention to use were borrowed from Venkatesh et al. (2003). Digital literacy and information literacy were measured using items from $\mathrm{Ng}$ (2012) and Ahmad et al. (2020) and Kurbanoglu et al. (2006). In total, 34 items and their contents were adapted for the use of digital technologies for teaching and learning purposes.

\subsection{Data collection}

To attain the opinions and experiences of the research target group - university staff and students - data was collected in June 2019 over the course of five weeks. The questionnaire consisted of three sections: questions concerning the respondent background, conceptual model construct items, and an open-text field where respondents could provide any additional insights regarding their experiences. The background information questions addressed respondent gender, age, access to digital technologies, frequency of use of digital technology, and self-reported proficiency level with digital tools. In terms of the items used to measure the construct in the model, respondents were advised to answer questions on a seven-point Likert scale ranging from one ("Strongly disagree") to seven ("Strongly agree"). Pilot testing and the respondent debriefing were conducted with a small group of participants (university lecturers, professors, and students) before distributing the questionnaire to assess reliability and comprehension (Hess and Singer 1995). The questionnaire was then distributed through various channels, including survey invitations through university staff and students' emails and university-related groups on social media sites. Additionally, flyers were distributed at four campuses of three Finnish universities in Finland.

\section{Data analysis}

Over 500 invitations were sent to potential respondents and we received 257 responses. After the removal of unengaged respondents and incomplete responses, 249 responses were eligible for further analysis. In terms of the respondents' current position within the university, the majority-153(61.4\%)—reported to be students, $90(36.1 \%)$ were teaching and research staff, eight (3.2\%) were administration staff, and 29 (11.6\%) employees had other duties at the university. The question assessing occupation within the university consisted of a multiple-choice matrix, meaning that respondents who identified both as staff and as administrative personnel did not have to choose between the two roles.

\subsection{Descriptive analysis}

Of 249 respondents, $147(59.0 \%)$ females and 99 (39.8\%) males, the remaining three $(1.2 \%)$ identifying as "other", 153 were students and 96 were university staff and others. The majority of the respondents $(58.6 \%)$ were aged 20-29 years. In terms of the highest level of education $87(34.9 \%)$ were reported to hold a bachelor's degree, 57 
(22.9\%) a PhD, $53(21.3 \%)$ a master's degree, and $49(19.7 \%)$ a high school diploma. Table 1 shows the descriptive results regarding the access to digital devices. Respondents were asked to rate their access (use) to smartphone, tablet, desktop PC, laptop and wearable devices in their day-to-day activities, ranging from "I do not use" to "Several times each day." For example, almost all respondents reported that they use their smartphones several times each day. The highest average use of digital devices was smartphones $(M=4.94)$ and laptops $(M=4.31)$, while the least used digital devices were wearable devices $(M=1.68)$ and tablets $(M=2.05)$. When we compared the results between university staff and students, some interesting results emerged. For instance, it was clear that as much as two-thirds of the university staff used tablets, whereas 90 students indicated that they did not use tablets at all. Among students, 49 indicated that they do not use desktop PCs, whereas only 16 university staff reported that they do not use PCs anymore.

Moreover, as shown in Table 2, we asked respondents to report the frequency of use of digital technologies (software and applications) in their day-to-day activities, ranging from "I do not use" to "Several times each day." The results showed that the most frequently used application was reported to be email $(\mathrm{M}=4.77)$, followed by social media $(M=4.57)$. When we compared staff and students' frequency of use of software (application), 129 students indicated that they use social media and 113 indicated that they use email applications several times each day. The results for the university staff showed that they all use email applications on daily basis and 62 reported that they use social media applications several times each day.

Table 3 shows the descriptive results regarding the respondents' proficiency with digital technologies (software or applications). The respondents were asked to report their level of proficiency with (word processor, spreadsheet, PPT slides, file sharing, photo editing, website management tools, mobile calendar, email applications and social media platforms) on a scale ranging from one ("Not proficient at all") to seven ("Very proficient"). The results show that the majority of the respondents were confident that they had a high level of proficiency with such digital technologies (software and applications). For example, the average proficiency rate regarding the use of word processors was $(M=5.91)$, followed the use of social media $(M=5.52)$. However, the highest proficiency rate concerned the use of email $(M=6.11)$. The

Table 1 Access (use) to digital technology

\begin{tabular}{llllll}
\hline Self-rating report & \multicolumn{4}{l}{ Access to digital technologies (\%) } & \\
\cline { 2 - 5 } & Smartphone & Tablet & Desktop PC & Laptop & Wearable devices \\
\hline I do not use & .4 & 51.8 & 27.6 & 1.2 & 78.2 \\
A few times a month or less & .8 & 21.0 & 22.2 & 6.6 & 3.9 \\
A few times a week & 0 & 8.9 & 10.1 & 13.6 & 1.6 \\
About once a day & 1.2 & 7.4 & 5.4 & 17.5 & 3.9 \\
Several times each day & 97.7 & 10.9 & 34.6 & 61.1 & 12.5 \\
Mean and Std. deviation & $4.94(.38)$ & $2.05(1.37)$ & $2.97(1.67)$ & $4.31(1.01)$ & $1.68(1.41)$ \\
\hline
\end{tabular}




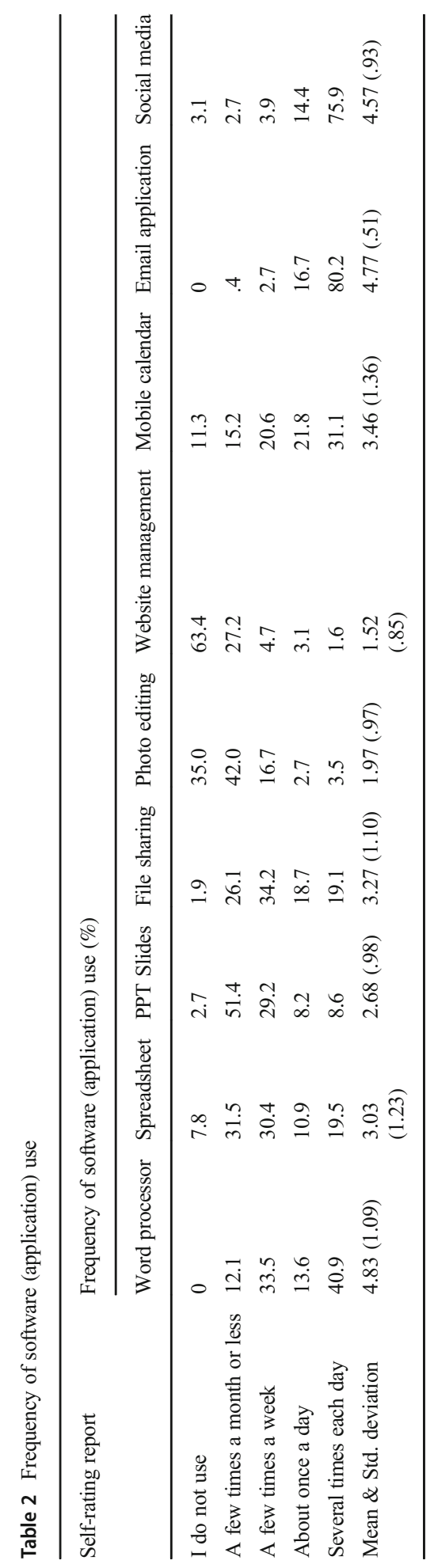




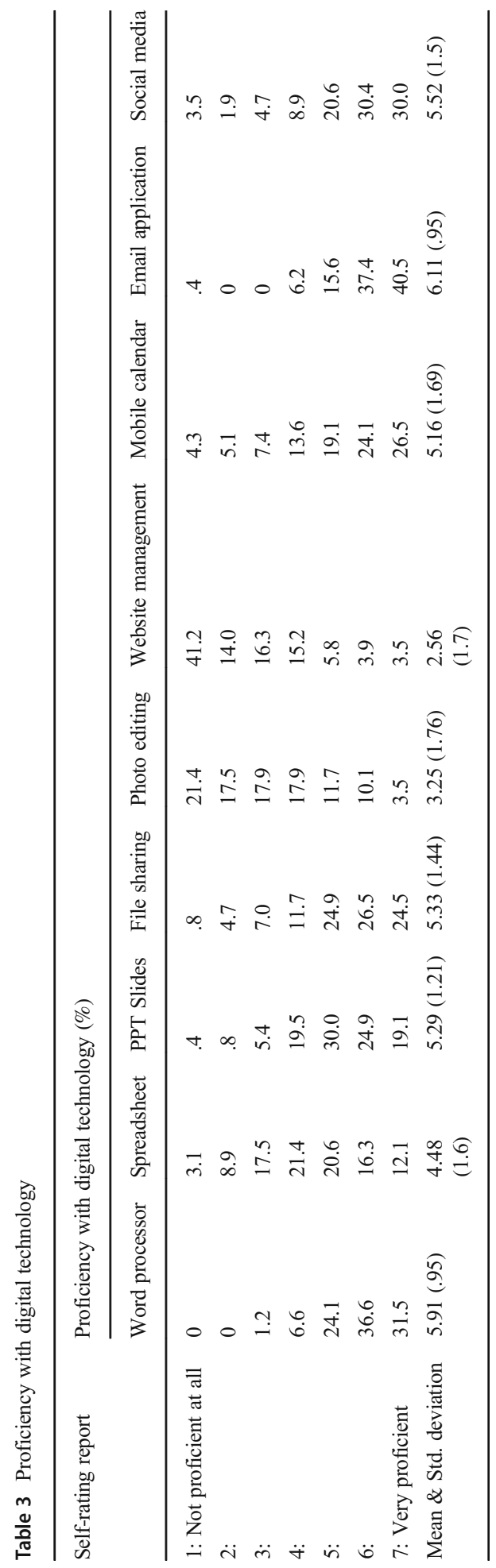


Table 4 Descriptive statistics, convergent validity, and internal consistency and reliability of items

\begin{tabular}{|c|c|c|c|c|c|c|c|}
\hline Constructs & Item & Factor loadings & Mean & Std & Cronbach's Alpha & $\mathrm{CR}$ & AVE \\
\hline \multirow[t]{8}{*}{ Digital literacy } & DL1 & 0.85 & 4.96 & 1.55 & \multirow[t]{8}{*}{0.91} & \multirow[t]{8}{*}{0.92} & \multirow[t]{8}{*}{0.61} \\
\hline & DL2 & 0.88 & 5.38 & 1.32 & & & \\
\hline & DL3 & 0.85 & 4.80 & 1.46 & & & \\
\hline & DL4 & 0.86 & 4.59 & 1.64 & & & \\
\hline & DL5 & 0.76 & 5.37 & 1.32 & & & \\
\hline & DL7 & 0.70 & 5.67 & 1.11 & & & \\
\hline & DL8 & 0.71 & 5.52 & 1.28 & & & \\
\hline & DL9 & 0.67 & 5.52 & 1.26 & & & \\
\hline \multirow[t]{4}{*}{ Effort expectancy } & EE1 & 0.94 & 5.58 & 1.30 & \multirow[t]{4}{*}{0.95} & \multirow[t]{4}{*}{0.96} & \multirow[t]{4}{*}{0.86} \\
\hline & EE2 & 0.92 & 5.44 & 1.25 & & & \\
\hline & EE3 & 0.92 & 5.46 & 1.27 & & & \\
\hline & EE4 & 0.94 & 5.35 & 1.33 & & & \\
\hline \multirow[t]{10}{*}{ Information literacy } & IL1 & 0.75 & 5.77 & 1.03 & \multirow[t]{10}{*}{0.92} & \multirow[t]{10}{*}{0.93} & \multirow[t]{10}{*}{0.58} \\
\hline & IL10 & 0.77 & 5.58 & 1.18 & & & \\
\hline & IL2 & 0.79 & 5.79 & 1.03 & & & \\
\hline & IL3 & 0.71 & 5.86 & 1.02 & & & \\
\hline & IL4 & 0.78 & 5.92 & 1.16 & & & \\
\hline & IL5 & 0.73 & 5.87 & 1.07 & & & \\
\hline & IL6 & 0.80 & 5.44 & 1.34 & & & \\
\hline & IL7 & 0.73 & 4.99 & 1.62 & & & \\
\hline & IL8 & 0.75 & 5.01 & 1.64 & & & \\
\hline & IL9 & 0.81 & 5.70 & 1.21 & & & \\
\hline \multirow[t]{5}{*}{ Intention to use digital technology } & Int_1 & 0.83 & 6.48 & 0.89 & \multirow[t]{5}{*}{0.85} & \multirow[t]{5}{*}{0.90} & \multirow[t]{5}{*}{0.64} \\
\hline & Int_2 & 0.90 & 6.49 & 0.85 & & & \\
\hline & Int_4 & 0.79 & 6.50 & 0.93 & & & \\
\hline & Int_5 & 0.83 & 6.60 & 0.81 & & & \\
\hline & Int_6 & 0.64 & 6.13 & 1.13 & & & \\
\hline \multirow[t]{4}{*}{ Performance expectancy } & PE1 & 0.85 & 6.49 & 0.86 & \multirow[t]{4}{*}{0.85} & \multirow[t]{4}{*}{0.90} & \multirow[t]{4}{*}{0.69} \\
\hline & PE2 & 0.88 & 6.20 & 1.05 & & & \\
\hline & PE3 & 0.85 & 6.23 & 0.99 & & & \\
\hline & PE4 & 0.75 & 5.56 & 1.31 & & & \\
\hline
\end{tabular}

Note: $\mathrm{CR}=$ composite reliability; $\mathrm{AVE}=$ average variance extracted

lowest proficiency rate concerned the use of website management tools $(M=2.56)$, which was to be expected owing to the context of this research and the respondents' positions at the time of the study. When we compared staff and students' proficiency levels regarding the use of digital technologies, 63 students indicated that they were very proficient in the use of email applications, but only 53 indicated that they were very proficient in the use of social media platforms. This finding was unexpected, as we assumed that students of recent generations spend much of their time using different social media platforms. Regarding the university staff's proficiency with digital 
Table 5 Discriminant validity according to the Fornell-Larcker criterion

\begin{tabular}{llllll}
\hline Construct & DL & EE & IL & INT & PE \\
\hline Digital literacy & $\mathbf{0 . 8 0 5}$ & & & & \\
Effort expectancy & 0.818 & $\mathbf{0 . 9 2 6}$ & & & \\
Information literacy & 0.596 & 0.467 & $\mathbf{0 . 7 7 2}$ & & \\
Intention to use digital technology & 0.390 & 0.446 & 0.417 & $\mathbf{0 . 8 0 0}$ & 0.583 \\
Performance expectancy & 0.461 & 0.525 & 0.379 & $\mathbf{0 . 8 3 4}$ \\
\hline
\end{tabular}

technologies, seven indicated that they were not proficient with social media at all, while 40 indicated that they were very proficient.

\subsection{Measurement model results}

To assess the research model, we assessed both the measurement model and structural model. The measurement model's reliability and validity were determined through the examination of outer loadings, composite reliability (CR) and convergent validity as presented by average variance extracted (AVE). According to Hair et al. (2011), the values of the outer loadings, CR, and AVE should be above 0.70, 0.70, and 0.50, respectively. The values obtained for part of the data analysis comply with recommendations. However, a few items had low factor loadings and were eliminated from further analysis. In addition, all the Cronbach's alpha values were above the threshold of 0.70 (see Table 4 for more information).

\subsection{Discriminant validity}

The discriminant validity was examined according to the Fornell and Larcker (1981) criterion. As shown in Table 5, the discriminant validity was confirmed.

We additionally assessed the discriminant validity via the heterotrait-monotrait ratio of correlations (HTMT). This alternative to the classical criterion can be applied to measure discriminant validity by comparing formerly outlined threshold levels, such as 0.85 (Kline 2011) or 0.90 (Teo et al. 2008). As shown in Table 6, the results show that the discriminant validity was confirmed.

Table 6 Discriminant validity according to the HTMT

\begin{tabular}{|c|c|c|c|c|c|}
\hline Construct & DL & $\mathrm{EE}$ & $\mathrm{IL}$ & INT & $\mathrm{PE}$ \\
\hline \multicolumn{6}{|l|}{ Digital literacy } \\
\hline Effort expectancy & 0.875 & & & & \\
\hline Information literacy & 0.651 & 0.481 & & & \\
\hline Intention to use digital technology & 0.449 & 0.501 & 0.447 & & \\
\hline Performance expectancy & 0.522 & 0.587 & 0.408 & 0.682 & \\
\hline
\end{tabular}




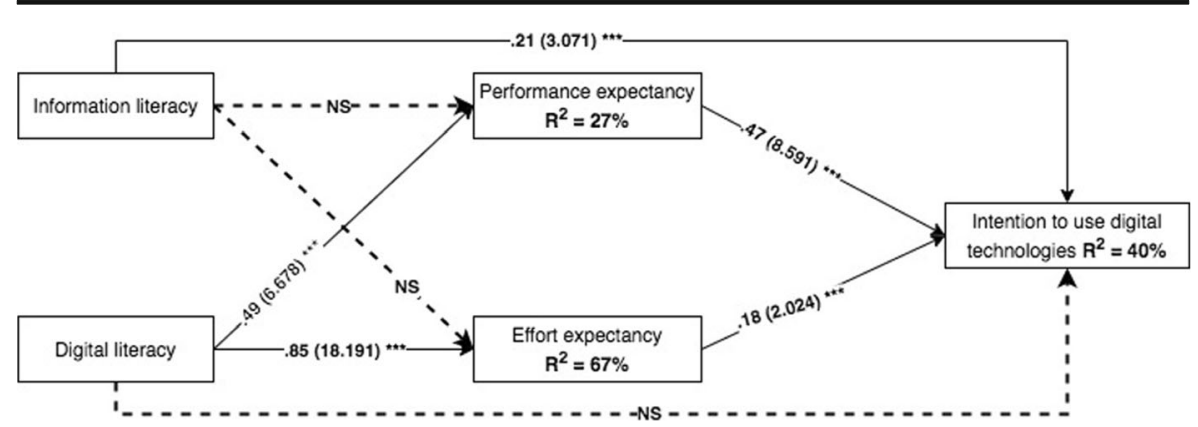

Fig. 2 Structural model results. Note: $* p$ value $<0.01$; ** $p$ value $<0.005$; *** $p$ value $<0.001$

\subsection{Structural model results}

To test the hypotheses and assess the statistical significance of the path coefficients in the research model, we used a structural equation modelling approach. PLS-SEM relies on the SRMR (standardized root mean square residual) value for model testing, of which the conservative recommended threshold is 0.08 . In our data, the value for the model fit is 0.07 . The intention to use digital technology is explained by a variance of $40 \%$. Both constructs of the UTAUT model-performance expectancy and effort expectancy — can be explained by variances of $27 \%$ and $67 \%$, respectively.

\subsection{Hypothesis testing}

Different alternative models were tested, and the model presented in Fig. 2 is the optimal model and best fits the data. The SEM results revealed a direct significant relationship between information literacy and intention to use digital technology ( $\beta=$ $0.21, t=3.071, p<0.001$ ); thus, H1a was supported by the model. Additionally, the SEM results revealed no direct significant relationships between information literacy and effort expectancy as well as information literacy and effort expectancy. Thus, both $\mathrm{H} 2 \mathrm{~b}$ and $\mathrm{H} 2 \mathrm{c}$ were rejected by the model.

Furthermore, the SEM results revealed that the path relationship between digital literacy and intention to use digital technology was not significant, thus rejecting $\mathrm{H} 2 \mathrm{a}$ in the model. Moreover, the SEM results revealed a direct significant relationship between digital literacy and performance expectancy $(\beta=0.48, t=6.678$, $p<0.001$ ), thereby supporting $\mathrm{H} 2 \mathrm{~b}$ in the model. The SEM results revealed that the relationship between digital literacy and effort expectancy was also significant ( $\beta=0.85, t=18.191, p<0.001$ ); thus, H2c is supported by the model. Moreover, the SEM results revealed a direct significant relationship between performance expectancy and intention to use digital technology $(\beta=0.47, t=8.591, p<0.001)$, thus providing theoretical support for $\mathrm{H} 3$ in the model. Finally, the SEM results revealed a direct significant relationship between effort expectancy and intention to use digital technology $(\beta=0.18, t=2.024, p<0.001)$; thus, $\mathrm{H} 4$ is supported by the model.

We also performed multi-group analysis to examine if the path relationships were different between students and staff. The MGA did not show any significant difference between the two groups except for one path. Such that the relationship between effort 
expectancy to intention to use digital technology was significant only for the students $(\beta=0.28, t=1.991, p<0.05)$.

\subsection{Mediation effect}

To examine the mediation effects of effort expectancy and performance expectancy on the paths between DL and IL to intention to use technology, we performed a mediation test. The results showed that both EE and PE mediate the relationship between DL and intention to use technology. This indicates that although we could not establish a direct relationship in this path, the entire effect of DL to intention to use was fully mediated through these two constructs. The paths between DL-EE-INT $(\beta=0.17, t=2.116$, $p<0.05)$ and the path between DL- PE-INT $(\beta=0.17, t=4.434, p<0.001)$ were found to be significant. Moreover, the mediation test results showed that the path between IL and intention to use was only mediated through PE $(\beta=0.08, t=2.090, p<0.05)$ and that EE did not mediate this path relationship.

\section{Discussion}

The use of digital technology for teaching and learning purposes seems to have become a common practice in university context. The conceptual model presented in this paper arises from (i) the need to highlight the importance of literacy skills in the context of technology use among university staff and students, and (ii) the call by Mohammadyari and Singh (2015), for further research on digital literacy. As a response to the said need and call, the research model sought to assess the intention to use digital technologies through a novel approach of combining technology adoption constructs with information literacy and digital literacy constructs. It has been argued that the research on literacy skills is a highly contemporary topic within higher education and a vital component in students' education and performance (e.g. Foo et al. 2014; Kanniainen et al. 2019).

In this paper, we proposed that a higher level of IL would have a direct effect on intention to use digital technology, as well as a positive impact on the productivity of university students and staff. In other words, we stated that a higher level of IL would influence the staff and students' performance and effort expectations in relation to using digital technology for teaching and learning purposes. Our findings confirmed two of the three hypotheses, as positive relationships were identified between IL and intention to use, as well as IL and performance expectancy. The relationship between IL and intention to use expands upon the findings of Nikou et al. $(2018,2019)$ where a relationship was found between IL and attitude towards the use of digital technologies, as well as attitude and intention to use. To the best of the authors' knowledge, there is a lack of studies to date confirming a relationship between IL and performance expectancy hence, there is a lack of alignment between the findings of our research and prior literature.

As with DL, we suggested that a higher level of DL would not only have a direct effect on intention to use digital technology, but also a positive impact on the productivity of university staff and students. In other words, we stated that DL would have a direct positive impact on staff and students' performance and effort expectations 
regarding the use of digital technology for teaching and learning purposes. The results of our research confirmed two of the three relationships, as we identified positive relationships between DL and performance expectancy, as well as DL and effort expectancy. These findings align with the findings of previous studies, e.g. Mohammadyari and Singh (2015).

Furthermore, we proposed that an individual with high levels of IL and DL skills might expect to put in less effort while using digital technologies for teaching and learning activities, and simultaneously expect to have a better performance. Subsequently, guided by the relationship within the UTAUT framework (Venkatesh et al. 2003), we hypothesised that performance expectancy would have a positive relationship with intention to use digital technology. Our findings confirmed this hypothesis, thus aligning the result with those of Ghalandari (2012) and Chávez Herting et al. (2020). Additionally, we theorised that an individual with high levels of IL and DL skills may expect to put in less effort while using digital technology for teaching and learning activities, and simultaneously expect to have a higher degree of ease associated with their use of technology. Subsequently, guided by the relationship within the UTAUT framework (Venkatesh et al. 2003), we hypothesised that effort expectancy would have a positive relationship with intention to use digital technology. The findings of our research confirmed this hypothesis, which aligns with the results of previous studies conducted by Ghalandari (2012) and Lowenthal (2010).

Moreover, the descriptive data analysis revealed some interesting aspects of the sample. In terms of the sample as a whole, when asked about access to digital technologies, the highest scoring variables when accounting for the mean were smartphones and laptops. In terms of the frequency of software application use, Microsoft Word processors and email services scored the highest. This was also the case with proficiency of software application use, as email services and Microsoft word processing services received the highest mean values. Clear differences were also identified between university staff and students, such as the fact that the use of tablets and desktop computers is more prominent among staff. In addition, another interesting finding was the fact that within the student sample, the number of respondents who considered themselves very proficient with email services was higher than the number of students who considered themselves very proficient with social media applications.

\section{Conclusion}

By applying performance expectancy and effort expectancy from the UTAUT framework (Venkatesh et al. 2003) accompanied by information literacy and digital literacy, this research builds upon prior literature through the development of a new conceptual model that aimed to explore university staff and students' intention to use digital technologies. The assessment of the developed model was then conducted using PLS-SEM. The research conducted in this paper could be considered a response to Silber-Varod et al. (2019), who stated that despite the importance of digital skills for effective learning in educational settings, research literature in this domain is marginal. The results of the current research provide support to earlier findings such as (Aavakare and Nikou 2020; Lea and Jones 2011), indicating that there is a complex interrelationship between literacies and technologies or (Nikou et al. 2020; Rosman et al. 2018), 
who indicated that information literacy skills do not necessarily imply that students employ the newly acquired skills for their own searches. Our findings are also supported by earlier results of (Mercader 2020, p. 5144), who stated that training and the level of digital skills are two factors that should be considered in the incorporation of digital technologies in higher education. The results of this research have several important implications both for curriculum design and for higher education policy. Firstly, the results show that both expectations regarding effort and performance have positive impacts on intention to use digital technology. These findings align with those of prior literature (Ghalandari 2012; Lowenthal 2010), and in the research at hand, the results reveal that university staff and students' intention to use digital technologies for teaching and learning purposes is impacted by their perceived expectations regarding performance and effort.

Secondly, the results indicate that a direct significant relationship exists between information literacy and the intention to use digital technology. This finding is aligned with those of prior findings such as (Rosman et al. 2018, p. 97), showing that the literacy skills are important for self-regulated learning since they allow individuals to construct their knowledge. Meanwhile, no such relationship could be identified between digital literacy and intention to use, despite our initial expectation. The lack of a significant relationship between digital literacy and intention to use could possibly be explained through the context of the research as well as the nature of the respondents participating in this research project. The sample consisted mainly of university students (millennials often known as digital natives) and university staff. These groups of people are assumed to be digitally literate individuals as they use, and have access to, various digital tools and applications in their daily teaching and learning tasks. Therefore, for them the use of digital technologies in their learning and teaching is a natural behaviour. The SEM, however, indicate that the impact of digital literacy on intention to use is mediated via performance expectancy and effort expectancy, thus establishing partial mediations. Some authors such as (Colwell et al. 2013), argue that digital literacy skills and capabilities are important for the students, as it seems locating and evaluating information found on the Internet are most challenging for them and teachers should have realistic expectations.

Thirdly, the findings of our research highlight specifically the importance of information literacy in relation to university staff and students' intention to use digital technologies. This is consistent with prior research of Colwell et al. (2013), who indicated that information literacy is important, as many students are reluctant to critically evaluate information found at multiple sites. Thus, there exists a need to emphasise the development of university staff and students' literacy skills in order to cope with the struggle within higher education environments mentioned by Gupta et al. (2020) - that is, to find the optimal ways to truly reap the benefits of educational digital technologies. Going beyond the promotion of digital tools within education, policy makers need to account and advocate for the literacy skills which ultimately will help with the acceptance of digital technologies within higher education institutes, as the effective and efficient use of these technologies depends on prerequisite skills such as digital literacy and information literacy (Avcı and Ergün 2019; Tang and Chaw 2016). Concludingly, strategies should be developed to encourage the progression of the dimensions of literacy that will facilitate the leap towards future educational technologies and expectations of future educational environments. 
Fourthly, for educational environments, selection of the relevant digital technology and harmonising it with the overall teaching and learning strategy is crucial for universities in order to reap the full benefits of emerging technologies. In addition, it is pivotal to understand the factors that influence university staff and students' intention to use digital technologies in their teaching and learning activities. The results of our research indicated that those higher education environments that nurture their employees and students and focus on holistic development also indirectly improve their core activities: teaching and learning.

\subsection{Limitations and future work}

As the data for this research was gathered via a self-completion survey, it is necessary to consider the limitation brought up by the inability to oversee respondent quality. Owing to the closed-ended survey questions, respondent answers were naturally limited. Further research could assess this limitation by incorporating qualitative approaches and expand the research in ways that allow for more open-ended answers (semi-structured interviews). In addition, further research on the topic should be conducted within other university settings, as the research at hand comprised of four campuses of three Finnish universities; therefore, generalising the findings is difficult. Thus, the knowledge on the subject matter could be expanded culturally and even comparatively between different types of university settings. Finally, the presented conceptual model could be elaborated upon through the inclusion of other constructs, such as computer self-efficacy.

Code availability Not available.

Authors' contributions All authors have equally contributed to the manuscript.

Funding Open Access funding provided by Abo Akademi University (ABO).

Data availability Available per request.

\section{Declarations}

Conflicts of interest/competing interests We have no conflicts of interest to declare.

Open Access This article is licensed under a Creative Commons Attribution 4.0 International License, which permits use, sharing, adaptation, distribution and reproduction in any medium or format, as long as you give appropriate credit to the original author(s) and the source, provide a link to the Creative Commons licence, and indicate if changes were made. The images or other third party material in this article are included in the article's Creative Commons licence, unless indicated otherwise in a credit line to the material. If material is not included in the article's Creative Commons licence and your intended use is not permitted by statutory regulation or exceeds the permitted use, you will need to obtain permission directly from the copyright holder. To view a copy of this licence, visit http://creativecommons.org/licenses/by/4.0/. 


\section{References}

Aavakare, M., \& Nikou, S. (2020). Challenging the concept of digital Nativeness-through the assessment of information literacy and digital literacy. In international conference on well-being in the information society (pp. 211-225). Cham: Springer.

Abu-Al-Aish, A., \& Love, S. (2013). Factors influencing students' acceptance of m-learning: An investigation in higher education. The International Review of Research in Open and Distance Learning, 14(5), 82107.

Ahmad, F., Widén, G., \& Huvila, I. (2020). The impact of workplace information literacy on organizational innovation: An empirical study. International Journal of Information Management, 51. https://doi.org/10. 1016/j.ijinfomgt.2019.102041.

Ajzen, I. (1985). From intentions to actions: A theory of planned behaviour. In action control (pp. 11-39). Berlin, Heidelberg: Springer.

Ala-Mutka, K. (2011). Mapping digital competence: Towards a conceptual understanding European Commission, Joint Research Centre, Institute for Prospective Technological Studies, Seville, 1-60. Retrieved from: ftp://s-jrcsvqpx102p.jrc.es/pub/EURdoc/JRC67075_TN.pdf. Accessed 06 Feb 2021

Alateyah, S., Crowder, R. M., \& Wills, G. B. (2013). Factors affecting the citizen's intention to adopt egovernment in Saudi Arabia. International Journal of Social, Human Science and Engineering, 7(9), 8085 .

Ali, R., \& Gupta, S. (2019). Investigating information literacy in business majors. In proceedings of the 2019 AIS SIGED international conference on information systems education and research. Available at: https:// aisel.aisnet.org/siged2019/2, accessed 09.09.2020.

Almaiah, M. A., Alamri, M. M., \& Al-Rahmi, W. (2019). Applying the UTAUT model to explain the students' acceptance of Mobile learning system in higher education. IEEE Access, 7, 174673-174686.

American Library Association (ALA). (2000). Information literacy competency standards for higher education. http://www.ala.org/acrl/ilstandardlo.html.

Anthonysamy, L., Koo, A. C., \& Hew, S. H. (2020). Self-regulated learning strategies in higher education: Fostering digital literacy for sustainable lifelong learning. Education and Information Technology, 25, 2393-2414. https://doi.org/10.1007/s10639-020-10201-8.

Avc1, Ü., \& Ergün, E. (2019). Online students' LMS activities and their effect on engagement, information literacy and academic performance. Interactive Learning Environments, 1-14. https://doi.org/10.1080/ 10494820.2019.1636088.

Bayrakdaroğlu, A., \& Bayrakdaroğlu, F. (2017). A comparative analysis regarding the effects of financial literacy and digital literacy on internet entrepreneurship intention. Journal of Entrepreneurship and Development, 12(2), 27-38.

Blau, I., \& Shamir-Inbal, T. (2017). Digital competences and long-term ICT integration in school culture: The perspective of elementary school leaders. Education and Information Technologies, 22(3), 769-787.

Carvalho, A., Areal, N., \& Silva, J. (2011). Students' perceptions of blackboard and Moodle in a Portuguese university. British Journal of Educational Technology, 42(5), 824-841.

Chávez Herting, D., Cladellas Pros, R., \& Castelló Tarrida, A. (2020). Habit and social influence as determinants of PowerPoint use in higher education: A study from a technology acceptance approach. Interactive Learning Environments, 1-17. https://doi.org/10.1080/10494820.2020.1799021.

Chen, J. L. (2011). The effects of education compatibility and technological expectancy on e-learning acceptance. Computers \& Education, 57(2), 1501-1511.

Colwell, J., Hunt-Barron, S., \& Reinking, D. (2013). Obstacles to developing digital literacy on the internet in middle school science instruction. Journal of Literacy Research, 45(3), 295-324.

Davis, F. D. (1989). Perceived usefulness, perceived ease of use, and user acceptance of information technology. MIS Quarterly, 13(3), 319-340.

Dede, C. (2010). Comparing frameworks for $21^{\text {st }}$ century skills. In J. Bellanca \& R. Brandt (Eds.), 21st century skills (pp. 51-76). Bloomington, IN: Solution Tree Press.

Desjardins, R. (2001). The effects of learning on economic and social well-being: A comparative analysis. Peabody Journal of Education, 76(3-4), 222-246.

Desjardins, F., \& Van Oostveen, R. (2015). Faculty and student use of digital technology in a 'laptop' university. In S. Carliner, C. Fulford, \& N. Ostashewski (Eds.), EdMedia: World Conference on Educational Media and Technology 2015 (pp. 990-996). Montreal: Association for the Advancement of Computing in Education (AACE).

Diep, N. A., Cocquyt, C., Zhu, C., \& Vanwing, T. (2016). Predicting adult learners' online participation: Effects of altruism, performance expectancy, and social capital. Computers \& Education, 101, 84-101. 
Dunn, K. (2002). Assessing information literacy skills in the California State University: A progress report. The Journal of Academic Librarianship, 28(1-2), 26-35.

Eisenberg, M. B. (2008). Information literacy: Essential skills for the information age. DESIDOC journal of library \& information technology, 28(2), 39-47.

Eshet-Alkalai, Y. (2004). Digital literacy: A conceptual framework for survival skills in the digital era. Journal of educational multimedia and hypermedia, 13(1), 93-106.

Fishbein, M., \& Ajzen, I. (1975). Belief, attitude, intention, and behaviour: An introduction to theory and research. Reading, MA: Addison-Wesley.

Foo, S., Majid, S., Azura Mokhtar, I., Zhang, X., Chang, Y.-K., Luyt, B., \& Theng, Y. L. (2014). Information literacy skills of secondary school students in Singapore. Aslib Journal of Information Management, 66(1), 54-76. https://doi.org/10.1108/AJIM-08-2012-0066.

Fornell, C., \& Larcker, D. F. (1981). Evaluating structural equation models with unobservable variables and measurement error. Journal of Marketing Research, 18(1), 39-50.

Georgina, D. A., \& Hosford, C. C. (2009). Higher education faculty perceptions on technology integration and training. Teaching and Teacher Education, 25(5), 690-696.

Ghalandari, K. (2012). The effect of performance expectancy, effort expectancy, social influence and facilitating conditions on acceptance of e-banking services in Iran: The moderating role of age and gender. Middle East Journal of Scientific Research, 12(6), 801-807.

Gross, M., \& Latham, D. (2012). What's skill got to do with it? Information literacy skills and self-views of ability among first-year college students. Journal of the American Society for Information Science and Technology, 63(3), 574-583.

Gullikson, S. (2006). Faculty perceptions of ACRL's information literacy competency standards for higher education. The Journal of Academic Librarianship, 32(6), 583-592.

Gupta, R., Seetharaman, A., \& Maddulety, K. (2020). Critical success factors influencing the adoption of digitalisation for teaching and learning by business schools. Education and Information Technologies, 25, 1-22. https://doi.org/10.1007/s10639-020-10246-9.

Hair, J. F., Ringle, C. M., \& Sarstedt, M. (2011). PLS-SEM: Indeed, a silver bullet. Journal of Marketing Theory and Practice, 19(2), 139-152.

Hair, J. F., Hult, G. T. M., Ringle, C., \& Sarstedt, M. (2017). A primer on partial least squares structural equation modelling (PLS-SEM) (2nd ed.). Sage publications.

Hair, J. F., Risher, J. J., Sarstedt, M., \& Ringle, C. M. (2019). When to use and how to report the results of PLS-SEM. European Business Review, 31(1), 2-24.

Heider, K. (2009). Information literacy: The missing link in early childhood education. Early Childhood Education Journal, 36(6), 513-518.

Hess, J., \& Singer, E. (1995). The role of respondent debriefing questions in questionnaire development. In: Proceedings of the Annual Conference of American Association for Public Opinion Research (pp 10751080). Fort Lauderdale, FL: AAPOR.

Jacobs, G. E. (2006). Fast times and digital literacy: Participation roles and portfolio construction within instant messaging. Journal of Literacy Research, 38(2), 171-196.

Jeffrey, L., Hegarty, B., Kelly, O., Penman, M., Coburn, D., \& McDonald, J. (2011). Developing digital information literacy in higher education: Obstacles and supports. Journal of Information Technology Education: Research, 10(1), 383-413.

Johnston, B., \& Webber, S. (2003). Information literacy in higher education: A review and case study. Studies in Higher Education, 28(3), 335-352.

Kanniainen, L., Kiili, C., Tolvanen, A., Aro, M., \& Leppänen, P. H. (2019). Literacy skills and online research and comprehension: Struggling readers face difficulties online. Reading and Writing, 32(9), 2201-2222.

Keefe, E. B., \& Copeland, S. R. (2011). What is literacy? The power of a definition. Research \& Practice for Persons with Severe Disabilities, 36(3-4), 92-99.

Kline, R. B. (2011). Principles and practice of structural equation modelling. New York: Guilford Press.

Kong, J., Deng, S., \& Zhang, Y. (2019). Research on influencing factors of college students' intention of online health information behaviour based on social cognitive theory. Journal of Physics: Conference Series, 1213(2), 022017. https://doi.org/10.1088/2F1742-6596/2F1213/2F2/2F022017.

Kurbanoglu, S. S., Akkoyunlu, B., \& Umay, A. (2006). Developing the information literacy self-efficacy scale. Journal of Documentation, 62(6), 730-743.

Lazar, I. M., Panisoara, G., \& Panisoara, I. O. (2020). Digital technology adoption scale in the blended learning context in higher education: Development, validation and testing of a specific tool. PLoS One, 15(7), e0235957.

Lea, M. R., \& Jones, S. (2011). Digital literacies in higher education: Exploring textual and technological practice. Studies in Higher Education, 36(4), 377-393. 
Leahy, D., \& Dolan, D. (2010). Digital literacy: A vital competence for 2010? In IFIP international conference on key competencies in the knowledge society (pp. 210-221). Berlin, Heidelberg: Springer.

Lewin, C., \& McNicol, S. (2015). Supporting the development of 21st century skills through ICT. In T. Brinda, N. Reynolds, R. Romeike, \& A. Schwill (Eds.), KEYCIT 2014: Key competencies in informatics and ICT (pp. 98-181). Potsdam, Germany: Universitätsverlag Potsdam.

Liu, Q., Geertshuis, S., \& Grainger, R. (2020). Understanding academics' adoption of learning technologies: A systematic review. Computers \& Education, 151, 103857. https://doi.org/10.1016/j.compedu.2020. 103857.

Lloyd, A. (2006). Information literacy landscapes: An emerging picture. Journal of Documentation, 62(5), $570-583$.

Lodge, J. M., Kennedy, G., \& Lockyer, L. (2019). Digital learning environments, the science of learning and the relationship between the teacher and the learner. In A. Carroll, R. Cunnington, \& A. Nugent (Eds.), Learning under the lens: Applying findings from the science of learning to the classroom. Abingdon: CRC Press.

Lowenthal, J. N. (2010). Using mobile learning: Determinates impacting behavioural intention. The American Journal of Distance Education, 24(4), 195-206.

Major, L., Warwick, P., Rasmussen, I., Ludvigsen, S., \& Cook, V. (2018). Classroom dialogue and digital technologies: A scoping review. Education and Information Technologies, 23(5), 1995-2028.

Martin, A. (2006). A European framework for digital literacy. Nordic Journal of Digital Literacy, 1(02), 151161.

Mercader, C. (2020). Explanatory model of barriers to integration of digital technologies in higher education institutions. Education and Information Technology, 25, 5133-5147. https://doi.org/10.1007/s10639-02010222-3.

Meyers, E. M., Erickson, I., \& Small, R. V. (2013). Digital literacy and informal learning environments: An introduction. Learning, Media and Technology, 38(4), 355-367.

Mohammadyari, S., \& Singh, H. (2015). Understanding the effect of e-learning on individual performance: The role of digital literacy. Computers \& Education, 82, 11-25.

Nassuora, A. B. (2012). Students' acceptance of mobile learning for higher education in Saudi Arabia. American Academic \& Scholarly Research Journal, 4(2), 24-30.

$\mathrm{Ng}$, W. (2012). Can we teach digital natives digital literacy? Computers \& Education, 59(3), 1065-1078.

Nikou, S., Brännback, M., \& Widén, G. (2018). The impact of multidimensionality of literacy on the use of digital technology: Digital immigrants and digital natives. In international conference on well-being in the information society (pp. 117-133). Cham: Springer.

Nikou, S., Brännback, M., \& Widén, G. (2019). The impact of digitalization on literacy: Digital immigrants vs. digital natives. In proceedings of the 27th European conference on information systems (ECIS), Stockholm \& Uppsala, Sweden, June 8-14. http://aisel.aisnet.org/ecis2019_rp/39

Nikou, S., Molinari, A., \& Widén, G. (2020). The interplay between literacy and digital technology: A fuzzyset qualitative comparative analysis approach. Information Research, 25(4), paper isic2016. DOI: https:// doi.org/10.47989/irisic2016.

Pastore, S., \& Andrade, H. L. (2019). Teacher assessment literacy: A three-dimensional model. Teaching and Teacher Education, 84, 128-138.

Rabah, J. (2015). Benefits and challenges of information and communication technologies (ICT) integration in Québec English schools. Turkish Online Journal of Educational Technology-TOJET, 14(2), 24-31.

Rachmadtullah, R., Marianus Subandowo, R., Humaira, M. A., Aliyyah, R. R., Samsudin, A., \& Nurtanto, M. (2020). Use of blended learning with Moodle: Study effectiveness in elementary school teacher education students during the COVID-19 pandemic. International Journal of Advanced Science and Technology, 29(7), 3272-3277.

Rosman, T., Peter, J., Mayer, A. K., \& Krampen, G. (2018). Conceptions of scientific knowledge influence learning of academic skills: Epistemic beliefs and the efficacy of information literacy instruction. Studies in Higher Education, 43(1), 96-113.

Sarrab, M., Al-Shihi, H., \& Rehman, O. M. H. (2013). Exploring major challenges and benefits of m-learning adoption. Current Journal of Applied Science and Technology, 3(4), 826-839.

Shields, R., \& Chugh, R. (2018). Preparing Australian high school learners with 21st century skills. Paper presented at the 2018 IEEE International Conference on Teaching, Assessment, and Learning for Engineering (TALE) (pp. 1101-1106). New York, NY: IEEE.

Silber-Varod, V., Eshet-Alkalai, Y., \& Geri, N. (2019). Tracing research trends of 21st-century learning skills. British Journal of Educational Technology, 50(6), 3099-3118. 
Skulmowski, A., Rey, G., \& D. (2020). COVID-19 as an accelerator for digitalization at a German university: Establishing hybrid campuses in times of crisis. Human Behaviour and Emerging Technologies, 2(3), $212-216$.

Tang, C. M., \& Chaw, L. Y. (2016). Digital literacy: A prerequisite for effective learning in a blended learning environment? Electronic Journal of E-learning, 14(1), 54-65.

Teo, T. S. H., Srivastava, S. C., \& Jiang, L. (2008). Trust and electronic government success: An empirical study. Journal of Management Information Systems, 25(3), 99-132.

Turnbull, D., Chugh, R., \& Luck, J. (2019). Learning management systems: An overview. In A. Tatnall (Ed.), Encyclopedia of education and information technologies. Cham: Springer. https://doi.org/10.1007/978-3319-60013-0 248-1.

Van Laar, E., Van Deursen, A. J., Van Dijk, J. A., \& De Haan, J. (2017). The relation between 21st -century skills and digital skills: A systematic literature review. Computers in Human Behaviour, 72, 577-588.

Van Oostveen, R., \& Desjardins, F. (2013). Developing and implementing a new online bachelor program: Formal adoption of videoconferencing and social networking as a step towards m-Learning. In M. B. Nunes \& M. McPherson (Eds.), Proceedings of the IADIS International Conference on e-Learning (pp. 223-230). Prague, Czech Republic, Jul 23-26, 2013: International Association for Development of the Information Society.

Venkatesh, V., Morris, M. G., Davis, G. B., \& Davis, F. D. (2003). User acceptance of information technology: Toward a unified view. MIS Quarterly, 27(3), 425-478.

Venkatesh, V., Thong, J. Y., \& Xu, X. (2012). Consumer acceptance and use of information technology: Extending the unified theory of acceptance and use of technology. MIS Quarterly, 36(1), 157-178.

von Loh, S. G., \& Henkel, M. (2014). Information and media literacy in kindergarten. In European conference on information literacy (pp. 253-262). Cham: Springer.

Záhorec, J., Hašková, A., \& Munk, M. (2019). Teachers' professional digital literacy skills and their upgrade. European Journal of Contemporary Education, 8(2), 378-393.

Zheng, Y., Wang, J., Doll, W., Deng, X., \& Williams, M. (2018). The impact of organisational support, technical support, and self-efficacy on faculty perceived benefits of using learning management system. Behaviour \& Information Technology, 37(4), 311-319.

Publisher's note Springer Nature remains neutral with regard to jurisdictional claims in published maps and institutional affiliations. 